\title{
Manufacturing of thin-walled parts for machinery by selective laser melting
}

\author{
Vitaliy Bobyr ${ }^{1, *}$, Artem Deev ${ }^{1}$, Anton Zhukov $^{1}$, and Pavel Kuznetsov ${ }^{1}$ \\ ${ }^{1}$ NRC "Kurchatov Institute" - CRISM "Prometey", 191015, Saint-Petersburg, Russia
}

\begin{abstract}
The paper describes the technology of selective laser melting, as well as its capabilities in the manufacture of thin-wall honeycomb energy absorber (HEA). The effect of the technological parameters of the building process on the HEA walls' thickness is studied. Conformity analysis of the mass-dimensional characteristics of the finished composition with the predefined parameters of the 3D-CAD model is carried out. Dependencies of building parameterson the quality of the manufactured HEA are established, general recommendations for the practical use of technology in the creation of HEAare given.
\end{abstract}

\section{Introduction}

In recent years, one of the most promising ways of forming metal products with the required parameters is considered additive technology, in which the manufacturing of the product in the necessary spatialgeometric proportions occurs by sintering the powder layers with the help of a concentrated energy flux [1-2]. Of particular interest is the determination of the optimal technological parameters of the manufacturing process, which in turn will be decisive in determining the mechanical and operational properties of the product, manufacturability, material consumption and, ultimately, the cost of the product.

As is known, the honeycomb energy absorber (HEA) ensures the absorption of the impact energy, for example, in the case of its application in the landing spacecraft for soft landing, due to its deformation, taking into account the permissible overload. To accomplish this, the structure of the HEA must be quite complex and satisfy a set of mechanical properties.

The production of thin-wall HEA by the selective laser melting, in particular sintering of powder materials, is a promising direction for the manufacturing of complex shaped products for critical applications operating under intensive loads. Increasing capacity and speed of operation of modern technology require an improvement in the quality of energy absorbers to effectively quench energy during braking or in case of emergencies [3]. The using of laser technologies to create highly loaded parts and elements of technology will reduce the cost and time limits of production, as well as increase the reliability and durability of products, providing high physical and mechanical characteristics [4].

\section{Materials and experimental methods}

\footnotetext{
*Corresponding author: vitalybobyr@yandex.ru
}

The raw material used is the powder of 321 asthenic stainless steel, manufactured by JSC "Polema" (Russia). The chemical composition of the powder, determined by X-ray fluorescent analysis methods on the Niton XL3t and LECO CS744 units, is shown in Table 1, from which it is seen that it complies with the ASTM A 240 standard.

Table 1. Chemical composition of used powders.

\begin{tabular}{|c|c|}
\hline \multicolumn{2}{|c|}{ Basic alloying elements, \% by weight } \\
\hline $\mathrm{C}$ & 0,12 \\
\hline $\mathrm{Si}$ & 0,8 \\
\hline $\mathrm{Mn}$ & 0,8 \\
\hline $\mathrm{Cr}$ & 17,6 \\
\hline $\mathrm{Ni}$ & 10,3 \\
\hline $\mathrm{Mo}$ & 0,1 \\
\hline $\mathrm{Ti}$ & 0,6 \\
\hline
\end{tabular}

The particle size distribution of the powder measured in the Malvern Mastersizer 2000 using the Fraunhofer approximation's laser diffraction method is shown in Fig. 1. It can be seen that the 321 steel powder has a large fractional composition, but a small amount of fine particles is present. In general, the powder meets the requirements for powders for SLM technology. 


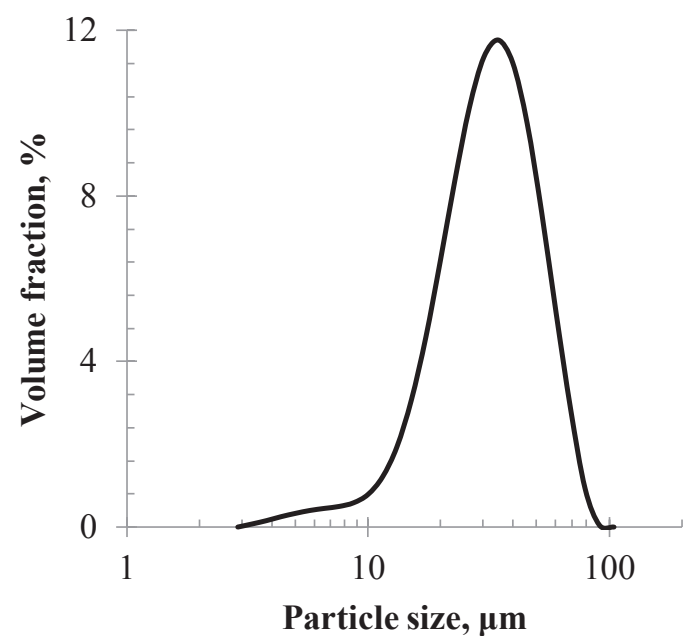

Fig. 1. The grain size distribution of 321 steel powders.

Selective laser melting of the powder was performed on the EOSINT M270 unit. The powder was melted under certain conditions: the 3-D model, developed in the AutoCAD environment, for the prototype of a HEA, is shown in Fig. 2.

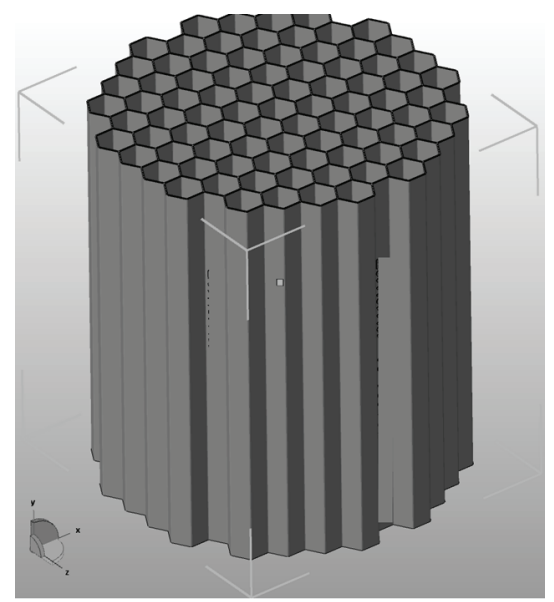

Fig. 2. Model of the HEAprototype.

The building of a detail by selective laser melting using a pre-designed model is carried out according to a certain algorithm presented on the Fig. 3 (for a single layer): DirectPart (a single detail layer):

- OuterSkin

- InnerSkin

- Counters

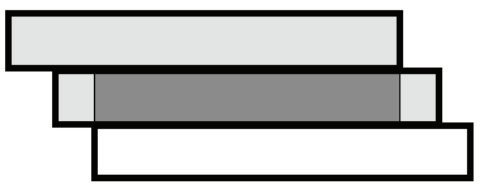

Fig. 3. Part of the detail with the overlay of three layers.

Proceeding from the fact that in the task it is necessary to build thin-walled honeycomb elements representing cylinders that are completely symmetric in the vertical direction (along the $\mathrm{Z}$ axis); Layers - the projections completely reflect each other without any displacements, and the wall thickness is $110 \mu \mathrm{m}, 130 \mu \mathrm{m}$ and $150 \mu \mathrm{m}$ (Fig. 4).

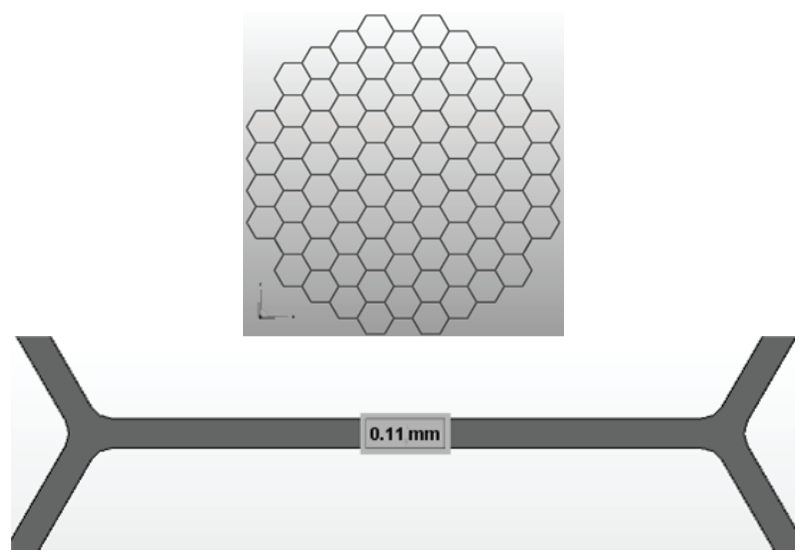

Fig. 4. Projection of a single layer of HEA in the horizontal plane XY, wall thickness $110 \mu \mathrm{m}$.

Accordingly, it was decided to build the HEA by the algorithm "in contours", i.e. excluding modes of additional melting of materialOuterSkinandInnerSkin (Fig. 5).

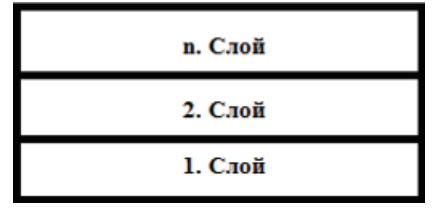

Fig. 5. Part of the detail with the overlay of three layers.

Thus, the required wall thicknesses of $110 \mu \mathrm{m}, 130$ $\mu \mathrm{m}, 150 \mu \mathrm{m}$ are sufficient to build "in contours", which in turn will result in the lowest heat input and, correspondingly, in the production of items.

To improve the accuracy of the HEA manufacturing and complete elimination of rejects, it is necessary to select the material meltingmode in the contour algorithm (counters). The main parameters of this mode are laser radiation power $\mathrm{P}(\mathrm{W})$, scanning speed of the laser beam $\mathrm{V}(\mathrm{mm} / \mathrm{s})$ and offset $(\mu \mathrm{m})$. Nominal values prescribed in the process unit $\mathrm{P}=120 \mathrm{~W}, \mathrm{~V}=400 \mathrm{~mm} / \mathrm{s}$, offset $=0 \mu \mathrm{m}$. Let us determine the coefficient of heat input $\mathrm{C}=\mathrm{P} / \mathrm{VW}$ $\cdot \mathrm{s} / \mathrm{mm}$, equal to $\mathrm{C}=0.3 \mathrm{~W} \cdot \mathrm{s} / \mathrm{mm}$. The offset parameter is responsible for shifting the laser beam relative to its center, with the positive offset shifting the beam toward the center (Fig. 6). Thus, for example, with offset $=10$ $\mu \mathrm{m}$, the centers of the laser beam will shift to each other and thus theoretically the wall thickness of the finished product will become less than the $3 \mathrm{D}$ model specified.

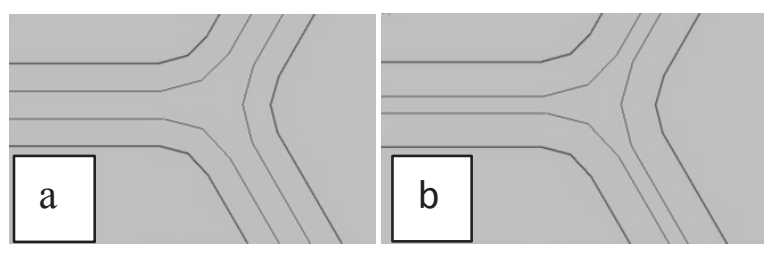

Fig. 6. Effect of the offset parameter on the path of the laser beam: offset $=0$ (a), offset $=10 \mathrm{~mm}(\mathrm{~b})$. 
In Table 2, the samples building parameters with a selection of the coefficient of heat input $\mathrm{C}=0.25 ; 12 \mathrm{C}=$ 0.35 , as a result of the change in power, as well as offset $=0 ; 0.002 ; 0.01 \mathrm{~mm}$, are presented.

The construction scheme is shownon Fig. 7, while the honeycomb elements are located along the wall thicknesses from $150 \mu \mathrm{m}$ to $110 \mu \mathrm{m}$ in the direction of movement of the mechanical knife for leveling the powder.

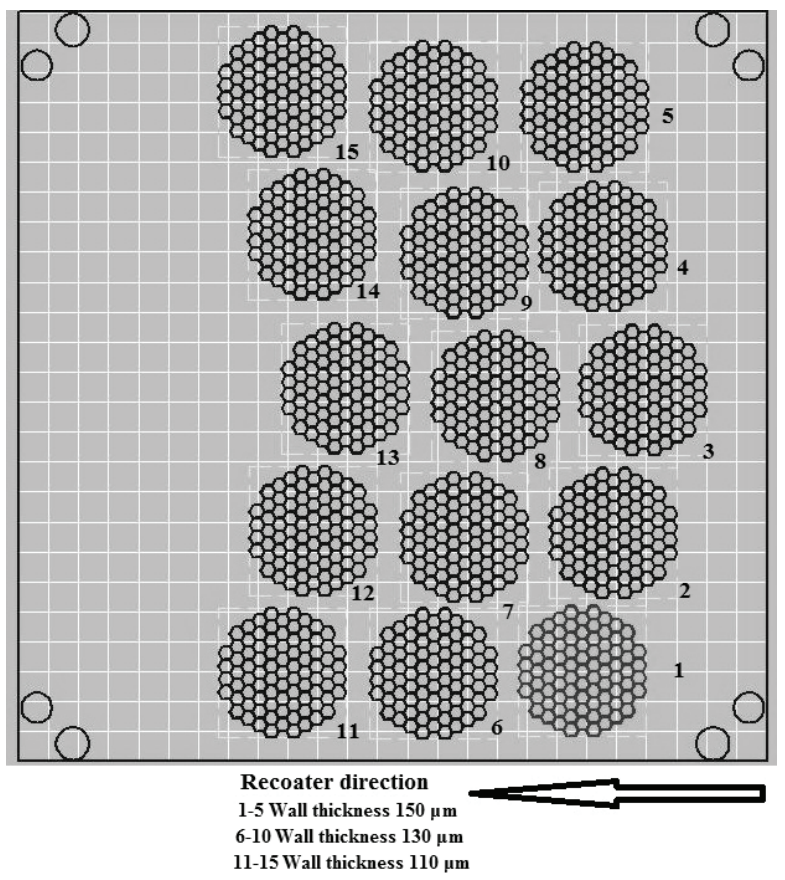

Fig. 7. Layout of honeycomb elements samples.

A large series of thicknesses $(150 \mu \mathrm{m})$ is located in the first row with respect to the direction of motion of the laser blade. Since it is not uncommon for the blade to hit the surface of the product during its production, also taking into account rather small thicknesses, it was decided to arrange the blanks, thus, as shown in the figure above. In turn, this almost completely eliminates the external mechanical effect on honeycomb elements with a small thickness of the walls, which makes it possible to produce a HEA without surface defects and defects of the structure itself.

Table 2. The samples building parameters.

\begin{tabular}{|c|c|c|c|}
\hline Sample № & $\begin{array}{c}\text { Wall thickness, } \\
\mu \mathrm{m}\end{array}$ & Offset, $\mu \mathrm{m}$ & $\mathrm{P}, \mathrm{W}$ \\
\hline 1 & 150 & 0 & 140 \\
\hline 2 & 150 & 0 & 100 \\
\hline 3 & 150 & 10 & 100 \\
\hline 4 & 150 & 10 & 140 \\
\hline 5 & 150 & 2 & 120 \\
\hline 6 & 130 & 2 & 120 \\
\hline 7 & 130 & 2 & 100 \\
\hline 8 & 130 & 2 & 140 \\
\hline 9 & 130 & 10 & 120 \\
\hline 10 & 130 & 0 & 120 \\
\hline 11 & 110 & 2 & 100 \\
\hline 12 & 110 & 0 & 140 \\
\hline 13 & 110 & 2 & 140 \\
\hline
\end{tabular}

\begin{tabular}{|c|c|c|c|}
\hline Sample № & $\begin{array}{c}\text { Wall thickness, } \\
\mu \mathrm{m}\end{array}$ & Offset, $\mu \mathrm{m}$ & $\mathrm{P}, \mathrm{W}$ \\
\hline 14 & 110 & 0 & 100 \\
\hline 15 & 110 & 2 & 120 \\
\hline
\end{tabular}

In the course of studying the results of HEA building on the first stage, it was suggested to make one more batch of products with the additional modes presented in Table 3 , and also to build two gradient samples.

Table 3. Additional samples building modes.

\begin{tabular}{|c|c|c|c|}
\hline Sample № & $\begin{array}{c}\text { Wall thickness, } \\
\mu \mathrm{m}\end{array}$ & Offset, $\mu \mathrm{m}$ & $\mathrm{P}, \mathrm{W}$ \\
\hline 1 & 150 & 0 & 80 \\
\hline 2 & 150 & 10 & 80 \\
\hline 3 & 130 & 0 & 80 \\
\hline 4 & 130 & 10 & 80 \\
\hline 5 & 110 & 0 & 80 \\
\hline 6 & 110 & 0 & 90 \\
\hline 7 & 110 & 0 & 85 \\
\hline 8 & 110 & 0 & 95 \\
\hline
\end{tabular}

The gradient sample is a customer's honeycomb element, divided into three parts in a horizontal plane, each of which is melted according to the specific mode indicated in Table 4.

Table 4. Gradient sample modes.

\begin{tabular}{|c|l|c|c|c|}
\hline $\begin{array}{c}\text { Sample } \\
\text { № }\end{array}$ & \multicolumn{1}{|c|}{ Modes } & $\begin{array}{c}\text { Wall } \\
\text { thickness, } \\
\mu \mathrm{m}\end{array}$ & $\begin{array}{c}\text { Offset, } \\
\mu \mathrm{m}\end{array}$ & $\mathrm{P}, \mathrm{W}$ \\
\hline \multirow{2}{*}{$9 *$} & $\begin{array}{l}\text { part 1 (from } \\
\text { the platform) }\end{array}$ & 110 & 0 & 120 \\
\cline { 2 - 5 } & part 2 & 110 & 0 & 100 \\
\cline { 2 - 5 } & part 3 & 110 & 0 & 80 \\
\hline \multirow{2}{*}{$10^{*}$} & $\begin{array}{l}\text { part 1 (from } \\
\text { the platform) }\end{array}$ & 130 & 0 & 120 \\
\cline { 2 - 5 } & part 2 & 130 & 0 & 100 \\
\cline { 2 - 5 } & part 3 & 130 & 0 & 80 \\
\hline
\end{tabular}

The obtained results of the building process for all the stages will make it possible to select those modes from the ones presented above for which the HEA made of the metal powders of stainless steels manufactured bytheselective laser melting will fully meet their specified 3D models both in geometry and in physical and mechanical properties.

\section{Experimental results and discussion}

Verification of the correspondence of the actual value of the wall thickness of thin-walled structures to the specified value:

With the electron microscope VEGA TESCAN, the images of the honeycomb structures shown in Fig. 8 (Platform No. 1) and 9 (Platform No. 2) were obtained, the purpose was to identify the possible presence of structural defects on the walls of the HEA. 
The results of comparison of the theoretical and actual values of wall thicknesses of honeycomb structures are presented in Table 5 .

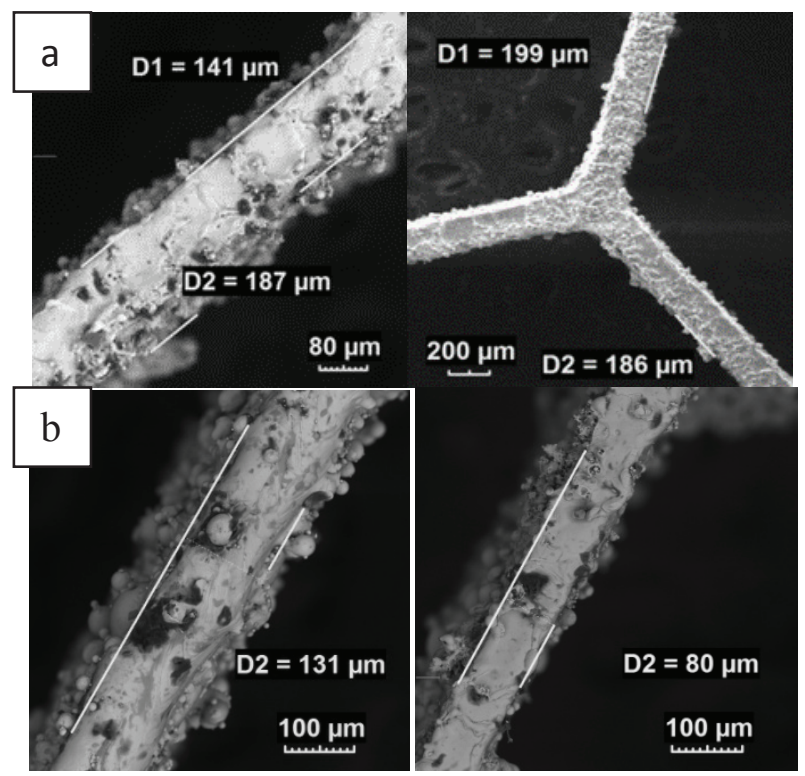

Fig. 8. Cellular structures from the platform 1 (a) and 2 (b).

As can be seen from the images shown in Fig. 8 (a) and (b), in general, the structure is slightly different in both cases. There are non-melted particles, but the structure continuity remains quite acceptable, there are no visible defects, such as microcracks caused by thermal stresses, and pores.

Table 5. Comparison of the theoretical and actual values of the wall thicknesses of HEA.

\begin{tabular}{|c|c|c|c|c|}
\hline \multirow{3}{*}{ 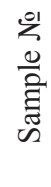 } & \multicolumn{2}{|c|}{ Platform №1 } & \multicolumn{2}{|c|}{ Platform №2 } \\
\hline & \multicolumn{2}{|c|}{ Wall thickness, $\mu \mathrm{m}$} & \multicolumn{2}{|c|}{ Wall thickness, $\mu \mathrm{m}$} \\
\hline & Theor. & Fact. & Theor & Fact. \\
\hline 1 & 150 & 145 & 150 & 129 \\
\hline 2 & 150 & 139 & 150 & 100 \\
\hline 3 & 150 & 116 & 130 & 102 \\
\hline 4 & 150 & 159 & 130 & 89 \\
\hline 5 & 150 & 151 & 110 & 80 \\
\hline 6 & 130 & 128 & 110 & 85 \\
\hline 7 & 130 & 117 & 110 & 82 \\
\hline 8 & 130 & 132 & 110 & 90 \\
\hline 9 & 130 & 129 & $110^{*}$ & $83 *$ \\
\hline 10 & 130 & 127 & $130^{*}$ & $107^{*}$ \\
\hline 11 & 110 & 92 & & \\
\hline 12 & 110 & 109 & & \\
\hline 13 & 110 & 124 & & \\
\hline
\end{tabular}

\begin{tabular}{|c|c|c|c|c|}
\hline \multirow{3}{*}{ 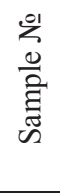 } & \multicolumn{2}{|c|}{ Platform №1 } & \multicolumn{2}{|c|}{ Platform №2 } \\
\hline & \multicolumn{2}{|c|}{ Wall thickness, $\mu \mathrm{m}$} & \multicolumn{2}{|c|}{ Wall thickness, $\mu \mathrm{m}$} \\
\hline & Theor. & Fact. & Theor. & Fact. \\
\hline 14 & 110 & 109 & & \\
\hline 15 & 110 & 108 & & \\
\hline
\end{tabular}

According to the presented data, it can be concluded that not always the actual values of the wall thicknesses of HEA coincide with the theoretically calculated ones. However, discrepancies can be leveled using the correction factor when creating a building model. The correction factor can be obtained by varying the power and speed parameters of the building.

The complex study of the influence of the technological modes on the HEA melting process showed the dependence of wall thicknessfrom the laser radiation power used. The values obtained can be explained by the presence of a small number of pores and other inclusions. Complex studies were carried out to determine the wall thicknesses, the mass of the HEA obtained, and also the static compression tests, since the main task of the HEA is to absorb the impact, the general data are given in Table 6.

Table 6. Characteristics of HEAbuild from 321 steel powder.

\begin{tabular}{|c|c|c|c|c|}
\hline \multirow{2}{*}{ 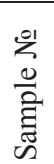 } & \multicolumn{2}{|c|}{ Weight, g } & \multicolumn{2}{|c|}{$\begin{array}{l}\text { Compression force, } \\
\text { kN }\end{array}$} \\
\hline & Theor. & Fact. & Activation & Compression \\
\hline 1 & 37,3 & 39,8 & 56,8 & 45,2 \\
\hline 2 & 37,3 & 34,4 & 46,2 & 33,3 \\
\hline 3 & 32,3 & 29,1 & 32,8 & 23,9 \\
\hline 4 & 32,3 & 36,0 & 44,1 & 35,8 \\
\hline 5 & 36,3 & 36,1 & 48,5 & 36,4 \\
\hline 6 & 31,4 & 31,3 & 36,0 & 28,0 \\
\hline 7 & 31,4 & 28,2 & 30,3 & 23,5 \\
\hline 8 & 31,4 & 35,7 & 43,9 & 34,6 \\
\hline 9 & 27,4 & 29,9 & 33,8 & 24,0 \\
\hline 10 & 32,4 & 32,3 & 41,0 & 29,8 \\
\hline 11 & 26,5 & 23,9 & 21,6 & 16,7 \\
\hline 12 & 27,5 & 34,3 & 39,6 & 30,9 \\
\hline 13 & 26,5 & 35,1 & 39,2 & 30,2 \\
\hline 14 & 27,5 & 24,8 & 23,5 & 18,7 \\
\hline 15 & 26,5 & 28,3 & 30,9 & 22,4 \\
\hline
\end{tabular}

The data showed in Table 6 relate to the process for the HEA manufacture with the melting of material 
between the contours. It should be noted that it was not possible to achieve full compliance with the given thicknesses, which could possibly be due to the multiparameter effect and the response of the material to thermal processes during laser melting. However, in a number of cases the difference between the theoretical and real HEA wall thicknesses is minimal and is of the order of 1-6 $\mu \mathrm{m}$. In turn, the mass of the HEA is within $+/-5 \mathrm{~g}$, which, in turn, is a fairly acceptable deviation.

Table 7. Characteristics of HEA build from 321 steel powder (construction in contours without shading).

\begin{tabular}{|c|c|c|c|c|}
\hline \multirow{2}{*}{ 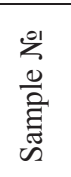 } & \multicolumn{2}{|c|}{ Weight, g } & \multicolumn{2}{|c|}{$\begin{array}{c}\text { Compression force, } \\
\mathrm{kN}\end{array}$} \\
\hline & Theor. & Fact. & Activation & $\begin{array}{c}\text { Compressi } \\
\text { on }\end{array}$ \\
\hline 1 & 37,3 & 32,3 & 41,1 & 26,3 \\
\hline 2 & 32,3 & 27,3 & 29,7 & 20,1 \\
\hline 3 & 32,4 & 27,1 & 28,0 & 20,0 \\
\hline 4 & 27,4 & 21,9 & 18,7 & 14,9 \\
\hline 5 & 27,5 & 21,7 & 18,0 & 14,3 \\
\hline 6 & 27,5 & 23,0 & 20,8 & 16,2 \\
\hline 7 & 27,5 & 22,2 & 17,7 & 15,5 \\
\hline 8 & 27,5 & 23,6 & - & 17,7 \\
\hline $9^{*}$ & 27,5 & 25,0 & 16,7 & $\begin{array}{l}14.6 / 18 \\
.3 / 23.9 \\
\end{array}$ \\
\hline $10^{*}$ & 32,4 & 29,6 & 27,4 & $\begin{array}{l}19.6 / 24 \\
.2 / 29.5\end{array}$ \\
\hline
\end{tabular}

According to Table 7, the mass of the HEA is also within $+/-5 \mathrm{~g}$. As for the HEA wall thickness values, in this case the construction was carried out at a laser radiation power of 80-95 W. It was assumed that in case of building only in circuits, it is necessary to use the minimum power. However, the variation in the values of the theoretical and actual thickness turned out to be larger than in the previous case. Below is a graph of the dependence of thickness on the technological modes, constructed on the basis of the above tables (Fig. 9).

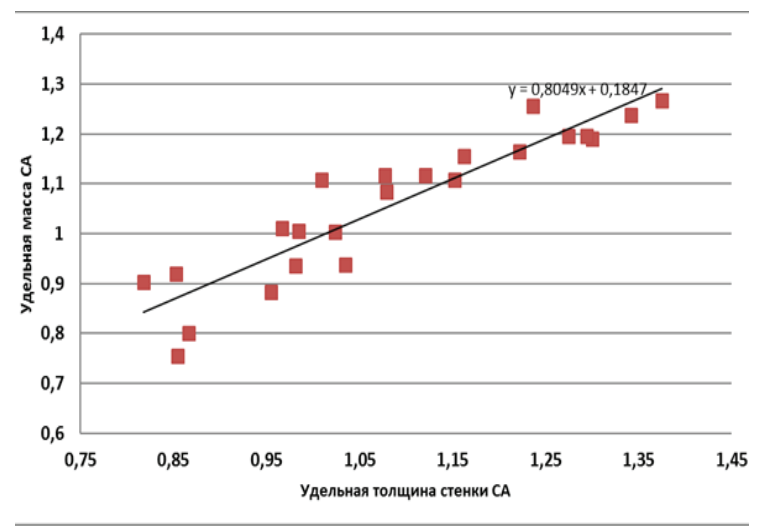

Fig. 9. Dependence of the specific mass on the HEA specific wall thickness.
This graph shows us the linear dependence of the specific mass on the specific wall thickness, thus confirming the absence or minimum number of pores and defects in the finished samples.

\section{Conclusions}

X-ray fluorescence analysis of the 321 metal powder showed that, on the whole, the elemental content of the alloying elements is within the permissible limits. The results of the granulometric analysis showed the particle size distribution of the powder material, where the largest volume percentage corresponds to a range of sizes on the order of 25-55 $\mu \mathrm{m}$, which fully meets the requirements for the raw material used for the laser fusion EOSINT M270.

When working out the modes of metal powder melting, for the subsequent manufacture of HEA, taking into account the small wall thicknesses (minimum size of $110 \mu \mathrm{m})$, it was decided to build the part "in contours", thereby avoiding additional thermal effects, thereby preventing the possible formation of both surface (open pores), and internal (microcracks) defects. The obtained results for all stages of building will make it possible to select those modes in which build honeycomb elements will fully meet their specified 3D models both in geometry and in physical and mechanical properties, excluding unevennesses.

According to the data from the scanning electron microscope, it can be concluded that the actual values of the HEA walls thicknesses do not always coincide with the theoretically calculated values. However, discrepancies can be leveled using the correction factor when creating a building model. The correction factor can be obtained by varying the power and speed parameters of the building. Structural studies have shown that a small amount of non-melted particles are present, but the structure continuity remains quite acceptable, there are no visible defects such as microcracks caused by thermal stresses and pores.

In general, the studies carried out made it possible to draw several important conclusions: in general, to achieve a given (or actual) thickness, the laser sintering power should be equal in value to the HEA wall thickness. In this case, it is assumed that the deviation will be minimal, both in thickness and in mass, respectively. To prevent the effects of external mechanical stress on the honeycomb elements in the building process with different thickness, the arrangement of the preforms on the platform is desirable to implement in rows, from the maximum to the minimum thickness. The HEA building mode in contours without hatching (melting between contours) does not introduce any structural differences in comparison with the standard mode.

This work was supported by the grant of Russian Scientific Fund №15-19-00210.

\section{References}

1. B.K. Barakhtin., A.V. Voznyuk, A.A. Deev, A.S. Zhukov, The structure - mechanical condition of 
addition material at hot plastic deform, Deformation and destruction of materials 2 (2017)

2. J. Sedlaka, D. Rican, Study of Materials Produced by Powder Metallurgy Using Classical and Modern Additive Laser Technology, Procedia Engineering 100, 1232-1241 (2015)

3. V.F. Aleshin, Landing devices of space vehicles (SV) on the basis offoams and honeycomb blocks (Science and education: electronic scientific and technical edition of the Bauman Moscow State Technical University, Moscow, 2010)

4. A. Hussein, L. Hao, Advanced lattice support structures for metal additive manufacturing, Journal of Materials Processing Technology 213, 1019-1026 (2013)

5. A.S. Oryshchenko, I.V. Gorynin, V.V. Bobyr, Additive technologies based on composite powder materials, Additive technologies in the Russian industry 22 (2015) 